\title{
(1)
}

\section{¿ES NECESARIO UN TRIBUNAL MULTILATERAL DE INVERSIONES?}

La inversión es un elemento fundamental para conseguir un crecimiento económico sólido y sostenible. La existencia de un marco político, jurídico y socioeconómico estable, abierto, transparente y no discriminatorio es crucial para fomentar las inversiones, especialmente las extranjeras. Los acuerdos internacionales de inversiones contribuyen a reducir el riesgo de las inversiones extranjeras al garantizar una serie de principios de protección y de no discriminación en el país receptor de la inversión. Además, incluyen un mecanismo de resolución de disputas inversor-Estado (ISDS, por las siglas de Investor-State Dispute Settlement), que se añade a los tribunales domésticos, para hacer efectiva la protección. Las críticas a este mecanismo ISDS han llevado a la Unión Europea a plantear una reforma con el objetivo final de crear un Tribunal Multilateral de Inversiones. Este tribunal, si bien contribuiría a fortalecer el marco internacional para realizar inversiones, necesitará de un respaldo de los países más importantes en la escena internacional, así como de la opinión pública.

Palabras clave: inversión extranjera directa, crecimiento económico, acuerdos internacionales de inversión, ISDS, organizaciones internacionales.

Clasificación JEL: F21, F43, F53, F55.

\section{Introducción}

La inversión extranjera directa (IED) es un factor fundamental en el crecimiento

\footnotetext{
* Economista. Jefe de Área de Comercio Internacional de Servicios e Inversiones, Ministerio de Economía, Industria y Competitividad, Secretaría de Estado de Comercio, Subdirección General de Comercio Internacional de Servicios e Inversiones.

El autor agradece los comentarios a versiones previas de este documento a D. José Antonio Zamora Rodríguez, Subdirector General de Comercio Internacional de Servicios e Inversiones.

Los errores, omisiones y opiniones que contiene este documento son de la exclusiva responsabilidad del autor $y$, por tanto, no necesariamente coinciden con los del Ministerio de Economía, Industria y Competitividad.

Versión de marzo de 2017.
}

económico ${ }^{1}$ y en la creación de empleo. Los países con un alto nivel de inversión consiguen sistemáticamente mayores niveles de desarroIlo. Por tanto, una cuestión fundamental para los Estados es cómo conseguir atraer inversión.

Cuando una empresa realiza un proyecto de inversión, previamente calcula el riesgo de dicho proyecto. Los factores no económicos que un inversor considera antes de realizar una inversión en un país extranjero son, entre $\square$

1 Kumari, 2014 
otros, la estabilidad política (riesgo político) y la seguridad jurídica (riesgo legal). De esta forma, podríamos decir que la IED está directamente relacionada con estos factores, es decir, ceteris paribus, a mayor estabilidad política y seguridad jurídica, mayor será el atractivo de un Estado para recibir inversiones.

Con este marco general de referencia y con el objetivo de fomentar las inversiones extranjeras, así como su protección, la comunidad internacional ha desarrollado una serie de acuerdos de inversión, bilaterales y multilaterales, en los que se protegen las inversiones y a los inversores extranjeros de un Estado cuando realiza inversiones en otro Estado. Estos acuerdos internacionales de inversión (AlI) garantizan un marco estable y predecible, fundamental para la realización de inversiones a largo plazo, y los Estados que los firman reconocen de forma vinculante una serie de principios de tratamiento al inversor extranjero.

Con respecto a la protección de inversiones, estos acuerdos incluyen un conjunto de disposiciones cuyos objetivos fundamentales son proteger al inversor extranjero contra la discriminación, contra la expropiación sin compensación y contra el trato injusto y no equitativo del Estado que recibe la inversión. Hay que señalar que este tipo de disposiciones son muy comunes en el ámbito del Derecho Mercantil Internacional. La creación, por ejemplo, de la Organización Mundial del Comercio (OMC) se basa en reglas que tratan de prevenir la discriminación.

Así pues, un aspecto importante de los All es que evitan la discriminación. Es decir, previenen un trato discriminatorio contra los inversores extranjeros frente a los inversores nacionales (los inversores extranjeros no deben recibir un trato peor que el trato que reciben los inversores nacionales) y frente a los inversores extranjeros de otros países (los privilegios que disfruten determinados inversores extranjeros deben extenderse a todos los inversores extranjeros). Esto permite unas reglas iguales para todos los inversores, fomentando la competencia, aumentando los beneficios para los consumidores e incrementando el crecimiento económico.

Para hacer efectivos los principios de protección de inversiones, estos All incluyen varios mecanismos de resolución de disputas inversor-Estado, entre ellos, un mecanismo 2 que permite al inversor demandar al Estado receptor de la inversión ante un tribunal arbitral internacional, si considera que dicho Estado ha violado los principios de protección de inversiones incluidos en el acuerdo firmado con otro Estado. Hay que destacar como refuerzo a la efectividad de este mecanismo que los laudos de los tribunales arbitrales son directamente ejecutables gracias a la Convención de Nueva York ${ }^{3}$ de 1958 y a la Convención del Centro Internacional de Arreglos de Diferencias Relativas a Inversiones ${ }^{4}$ (CIADI en adelante) de 1965. Sin este mecanismo de reclamación los principios de protección de inversiones incluidos en los acuerdos serían una declaración de intenciones.

El primer acuerdo internacional de inversiones ${ }^{5}$ lo firmaron Alemania y Pakistán en 1959 , y desde entonces estos acuerdos han tenido un crecimiento exponencial.

En la actualidad, los Estados miembros ${ }^{6}$ de la Unión Europea son parte en más de la $\triangleright$

\footnotetext{
2 Mecanismo de resolución de disputas inversor-Estado o InvestorState Dispute Settlement (ISDS, por sus siglas en inglés).

3 Convenio sobre reconocimiento y ejecución de sentencias arbitrales extranjeras, hecho en Nueva York el 10 de junio de 1958. https://www.boe. es/diario_boe/txt.php?id=BOE-A-1977-15727

4 https://icsid.worldbank.org/

5 http://www.iisd.org/pdf/2006/investment_pakistan_germany.pdf

6 A fecha de 15 de marzo de 2017 la UNCTAD tiene registrados 3.331 acuerdos bilaterales de inversión o acuerdos con disposiciones sobre inversiones. Los EE MM son parte en 1.763 (http://investmentpolicyhub. unctad.org/IIA).
} 
mitad de los más de 3.300 acuerdos internacionales de inversiones (All) que existen en el mundo. Estos acuerdos contienen acuerdos bilaterales de inversión o capítulos de inversión que se incluyen en los acuerdos de libre comercio (ALC).

España tiene 73 acuerdos de promoción y protección recíproca de inversiones ${ }^{7}$ (APPRI) que son valorados muy positivamente por las empresas españolas cuando realizan inversiones en el exterior.

Sin embargo, en los últimos tiempos, los All han sido muy criticados por la opinión pública, especialmente el mecanismo de solución de diferencias entre inversores y Estados (ISDS). Las críticas fundamentales se refieren a que este tipo de acuerdos dan la posibilidad a inversores privados a denunciar a Estados ante tribunales arbitrales constituidos ad hoc 8 por abogados especializados en la materia, fuera de la jurisdicción de dichos Estados, poniendo en riesgo su derecho a regular en interés público.

Aunque es cierto que algunos inversores han utilizado los All para demandar a los Estados por legislaciones promovidas por objetivos de interés público ${ }^{9}$, se trata de un número reducido de casos que han generado alarma social pero que no son representativos del razonable funcionamiento que el sistema ha tenido, en términos generales, hasta el momento.

Fuente: Secretaría de Estado de Comercio (http://www.comercio. es/eu-es/inversiones-exteriores/acuerdos-internacionales/acuerdospromocion-proteccion-reciproca-inversiones-appris/orriak/lista-apprivigor.aspx).

8 Ad hoc implica no permanente, es decir, constituidos para juzgar cada caso concreto.

9 Los casos que mayores críticas han generado en la opinión pública son los de la empresa Phillip Morris contra Australia por la aprobación de la legislación antipublicidad en las cajetillas de tabaco ( $h t t p: / /$ investmentpolicyhub.unctad.org/ISDS/Details/421) o el de la empresa Veolia contra Egipto por los salarios fijados en legislación laboral (http:// investmentpolicyhub.unctad.org/ISDS/Details/458).

\section{El mecanismo de resolución de disputas inversor-Estado (ISDS)}

Como se ha mencionado, el mecanismo de resolución de disputas inversor-Estado (ISDS) proporciona al inversor un instrumento que le permite iniciar una reclamación contra un Estado si considera que una medida adoptada por dicho Estado no respeta alguno de los estándares de protección de inversiones recogidos en el All y que perjudica su inversión.

Originariamente, el ISDS fue diseñado para asegurar un foro neutral, independiente, rápido y económico que ofreciera a los inversores un mecanismo para resolver sus disputas con los Estados. En su concepción téorica inicial, el hecho de que los inversores pudieran interponer reclamaciones ante tribunales arbitrales, contra actuaciones de Estados fuera de la esfera doméstica del Estado demandado, proporcionaba al inversor una garantía de un juicio imparcial.

Otra característica atractiva de este mecanismo es que proporciona a las partes en el conflicto un control considerable sobre el proceso. Por ejemplo, participando en la selección de los árbitros que analizarán la disputa o la posibilidad, bajo ciertas condiciones, de ejecutar el laudo arbitral en cualquier país miembro del Centro Internacional de Arreglos de Diferencias Relativas a Inversiones (CIADI).

El número de casos conocidos de ISDS $^{10}$ acumulados a finales de 2016 era de 767, mientras que el de reclamaciones interpuestas por inversores contra Estados en 2016 llegó a 62 (74 casos iniciados en 2015).

10 Según datos actualizados a 15 de marzo de 2017 por la UNCTAD (http://investmentpolicyhub.unctad.org/ISDS). 


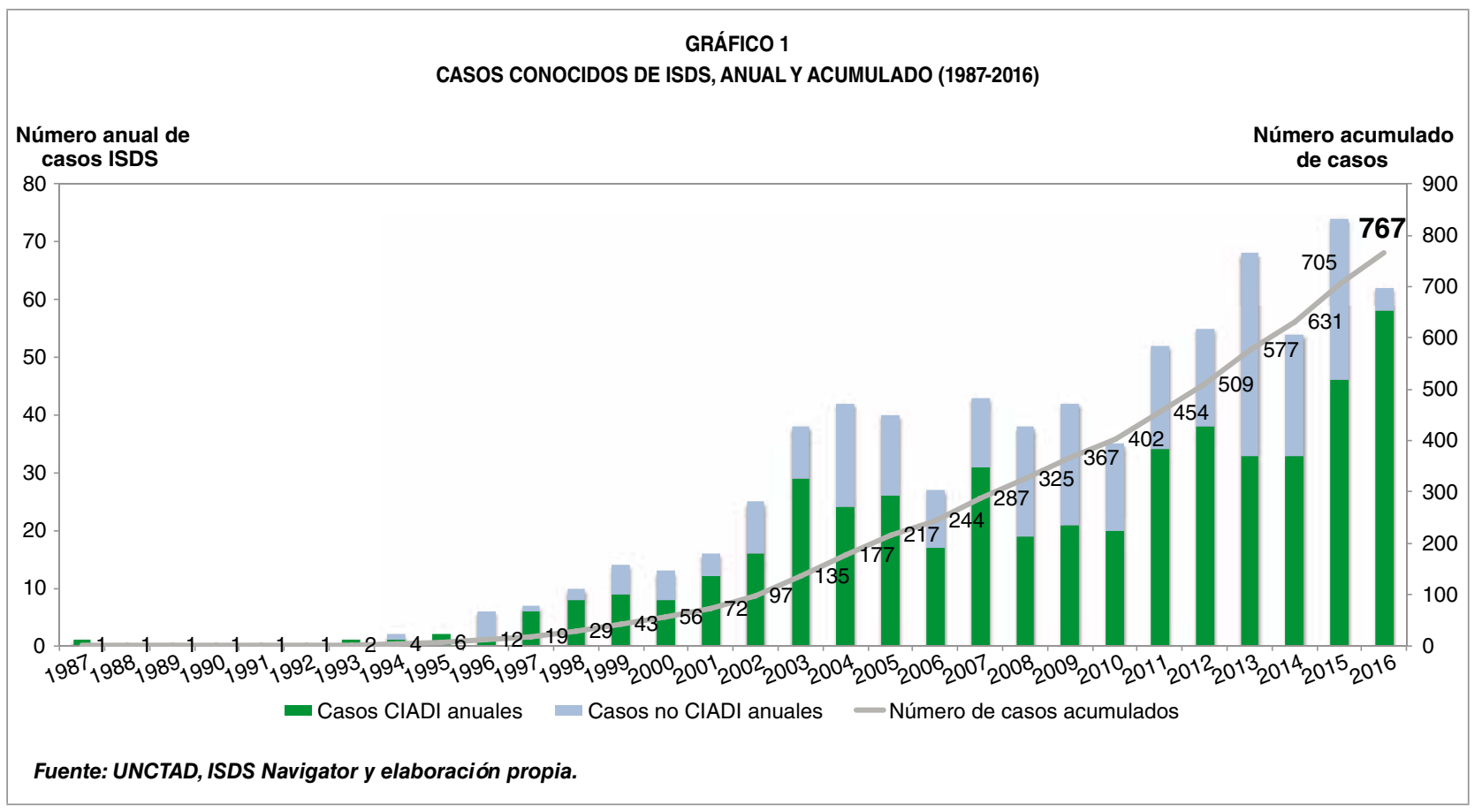

Del total de casos conocidos (767), 495 habían concluido a la fecha de elaboración de este artículo. Es interesante analizar los resultados de los laudos de los casos concluidos para ver con datos objetivos si es cierta una de las principales críticas que se hace al ISDS, que se trata de un mecanismo en beneficio de las multinacionales en contra de los Estados.

Pues bien, analizando los casos concluidos hasta la fecha, según la Conferencia de las Naciones Unidas sobre Comercio y Desarrollo (UNCTAD, por sus siglas en inglés), en un 36,4 por 100 de los casos la decisión del tribunal arbitral fue a favor del Estado demandado, mientras que en un 26,7 por 100 de los casos la decisión fue a favor del inversor demandante. Este dato objetivo supone que los Estados demandados obtienen mayor proporción de decisiones favorables que las empresas en los laudos arbitrales por disputas de inversión.

Además, hay que destacar que en un 24,4 por 100 de las ocasiones la disputa se resolvió antes de que el tribunal arbitral hubiera emitido un laudo. Esto indicaría que ha habido un «proceso de negociación» entre inversor y Estado en el que se ha producido un acuerdo antes de que el tribunal arbitral haya emitido un laudo. Finalmente, en un 12,5 por 100 el caso no fue finalizado por diferentes razones, aunque la fundamental es la falta del pago de la provisión de costes del tribunal.

Es importante señalar que los laudos arbitrales en casos ISDS suelen darse casi siempre en forma de compensación monetaria y casi nunca implican la restitución de la propiedad. Además, estos laudos no obligan al Estado demandado a que tenga que anular o modificar ninguna medida legislativa o administrativa adoptada.

No hay estudios que indiquen que los casos de ISDS afecten al comercio o a los flujos de inversión a nivel general, aunque sería razonable pensar que si un país recibe varias demandas de distintos inversores, en un mismo o diferentes sectores, la recepción de inversión extranjera podría verse afectada.

Ya hemos comentado anteriormente alguna crítica al ISDS realizada por sus detractores. No obstante, el ISDS también tiene defensores. $\square$ 
GRÁFICO 2

CASOS ISDS CONCLUIDOS: RESULTADO DE LAS DECISIONES

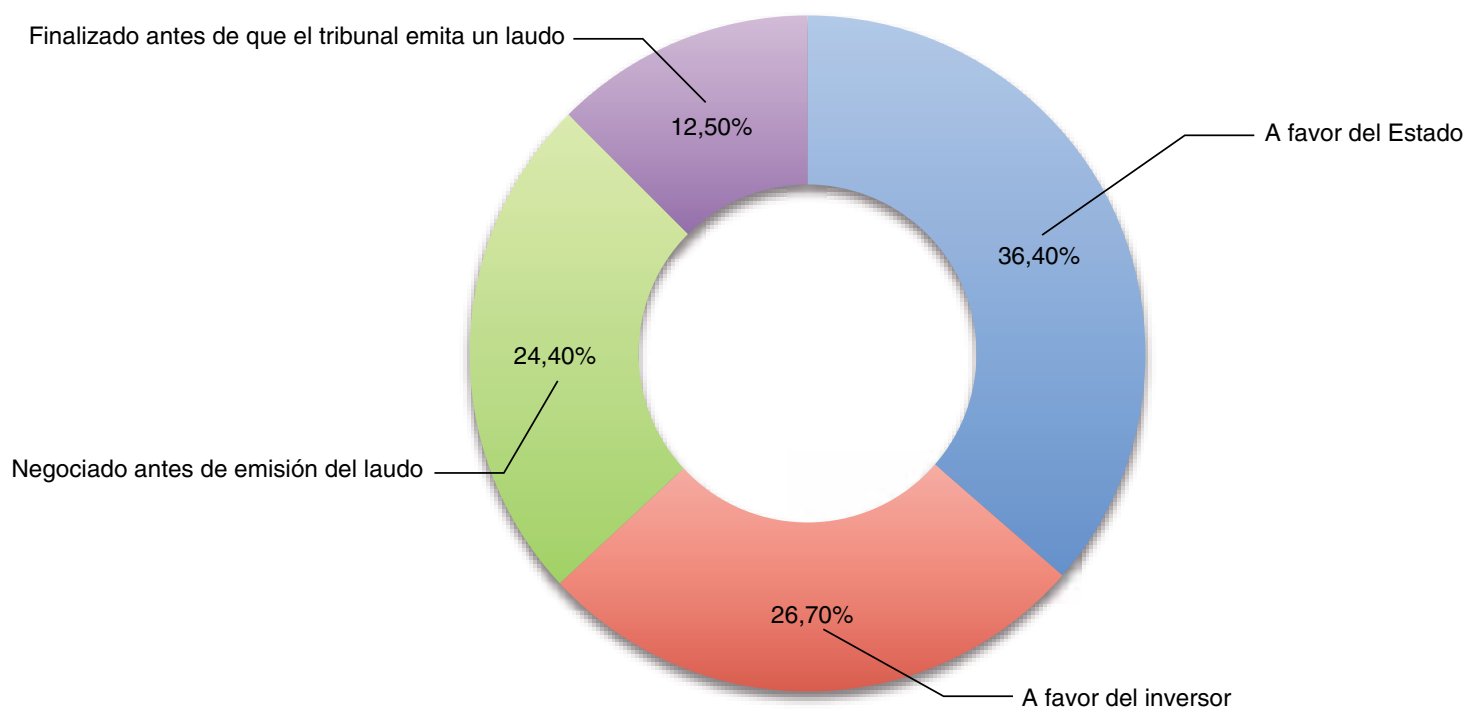

Fuente: UNCTAD (http://investmentpolicyhub.unctad.org/ISDS). Datos a 15 de marzo de 2017.

Los defensores del ISDS destacan que este mecanismo contribuye positivamente a promover un marco de principios de protección de inversiones homogéneo a nivel internacional, a incrementar los flujos de inversión mediante la reducción de los costes de financiación de la inversión al contribuir a mejorar la certidumbre del marco jurídico para realizar las inversiones y reducir su coste de financiación. Es decir, en cierto sentido, equivaldría a un seguro que cubre el riesgo político. Además, hay que indicar que el origen del ISDS fue tratar de despolitizar los conflictos de inversiones que, anteriormente a este mecanismo, eran tratados a nivel de Estado con el riesgo de que pudieran perjudicar las relaciones entre dichos Estados.

Otro elemento positivo del mecanismo ISDS es la ejecutabilidad de los laudos por parte del inversor. Hay diferentes reglas para iniciar un arbitraje ${ }^{11}$, siendo las más utilizadas las del

11 CIADI; UNCITRAL; Cámara de Comercio de Estocolomo; Corte Permanente de Arbitraje; etcétera.
CIADI. El Convenio de CIADI establece que los laudos arbitrales emitidos bajo sus reglas tendrán la misma ejecutabilidad ${ }^{12}$ que una sentencia firme en cualquier Estado contratante ${ }^{13}$. Esta característica confiere un gran valor para el inversor.

En los últimos años, pero especialmente con el inicio de las negociaciones del acuerdo de libre comercio (TTIP por sus siglas en inglés) entre la Unión Europea y Estados Unidos, han arreciado las voces críticas al ISDS.

Inicialmente, las críticas estaban asociadas con movimientos antiglobalización, pero han ido calando en gran parte de la opinión pública. Estas críticas identifican el ISDS como un instrumento al servicio de las multinacionales para demandar a los Estados y evitar que regulen en interés público y han provocado $\triangleright$

12 Artículo 54(1) Convenio CIADI: «(1) Todo Estado contratante reconocerá al laudo dictado conforme a este convenio carácter obligatorio y hará ejecutar dentro de sus territorios las obligaciones pecuniarias impuestas por el laudo como si se tratase de una sentencia firme dictada por un tribunal existente en dicho Estado...».

13 A 15 de marzo de 2017, 161 Estados forman parte de CIADI (https:// icsid.worldbank.org/en/Pages/about/Database-of-Member-States.aspx). 
que algunos países hayan denunciado ${ }^{14}$ la Convención de CIADI, hayan finalizado sus All ${ }^{15}$ o hayan revisado su modelo de All ${ }^{16}$.

Las críticas al ISDS se han centrado, en primer lugar, en la falta de independencia e imparcialidad de los árbitros. Solo los inversores pueden iniciar los casos contra los Estados, y por esta razón se considera que los árbitros estarán más inclinados a defender los intereses de los inversores que el de los Estados. No obstante, anteriormente hemos comentado que esta conclusión no se sustenta con los datos existentes.

Una segunda crítica se refiere a que el laudo arbitral es poco consistente y en ocasiones contraditorio, sin que exista un mecanismo adecuado que corrija o limite estas inconsistencias como lo haría, por ejemplo, un mecanismo de apelación. Esta falta de consistencia afectaría negativamente a la confianza y a la credibilidad del arbitraje de inversiones, lo que debilitaría el marco de las inversiones y, en última instancia, el crecimiento económico.

Costes excesivos y largos plazos de resolución son otras de las críticas que reciben los arbitrajes de inversiones, junto con la opinión de que este mecanismo confiere un poder a árbitros individuales, que no son parte del Estado, que no es democrático y viola el Estado de derecho.

Otra de las críticas reiteradas al ISDS es la opacidad y falta de transparencia de los procedimientos, al permitir la no publicación de ningún tipo de información sobre el procedimiento.

\footnotetext{
14 Países que han denunciado la Convención de CIADI: Bolivia (2007); Ecuador (2009) y Venezuela (2012).

15 Ecuador terminó 9 All; Venezuela terminó 1; Indonesia terminó 17 y Sudáfrica 9.

16 Brasil, en marzo de 2015, firmó con Mozambique su primer Acuerdo de Cooperación y Facilitación de Inversiones en la que no hay ISDS. India comunicó en 2016 su intención de negociar sus All con el objetivo de que el ISDS sea un mecanismo de resolución de conflictos accesorio.
}

\section{Reforma del sistema de protección de inversiones: propuesta de la UE}

\subsection{Presentación}

Las críticas mencionadas anteriormente están impulsando la reforma del sistema de protección de inversiones y, en particular, del mecanismo de solución de diferencias (ISDS).

En lo relativo a la falta de transparencia en los procedimientos arbitrales es donde se ha producido un mayor avance en los últimos años con varias reformas: 1 ) la modificación de la Convención de CIADI en 2006 introduciendo medidas que incrementan la transparencia; 2) la introducción de disposiciones sobre transparencia en los All, y 3) la mayor adopción de las reglas ${ }^{17}$ de transparencia UNCITRAL y de la Convención de Mauricio ${ }^{18}$.

Como consecuencia de estas reformas, el mecanismo ISDS es más transparente y ha aumentado la publicación de los laudos, documentos, audiencias públicas y la participación de terceros en los procedimientos (amicus curiae), aunque todavía queda mucho margen para incrementar la transparencia. Por ejemplo, mientras en los nuevos acuerdos comerciales que está negociando la UE se incluyen las reglas de transparencia UNCITRAL, en los acuerdos ya en vigor no hay disposiciones sobre transparencia.

La Convención de Mauricio permite ampliar la aplicación de las reglas de transparencia de UNCITRAL a los acuerdos de inversión firmados antes del 1 de abril de 2014. Esta convención permitiría incrementar de $\triangleright$

\footnotetext{
17 http://www.uncitral.org/uncitral/es/uncitral_texts/ arbitration/2014Transparency.html

18 https://www.uncitral.org/pdf/english/texts/arbitration/transparencyconvention/Transparency-Convention-e.pdf
} 
forma considerable la transparencia en los arbitrajes inversor-Estado abriendo las audiencias al público, permitiendo a las partes interesadas presentar comunicaciones al tribunal y poniendo a disposición del público los documentos relacionados con el arbitraje.

Por otro lado, en los últimos años se ha incrementado el debate sobre la creación de un tribunal permanente de inversiones bajo el argumento de que proporcionaría varias mejoras sobre el sistema actual.

La primera sería aumentar la consistencia y corrección legal de los laudos, lo que mejoraría el marco para la realización de las inversiones, dado que una institución permanente tiende a ofrecer mayor consistencia en sus decisiones que los tribunales ad hoc.

Una segunda mejora que se argumenta es que los jueces permanentes ofrecen una mayor garantía de imparcialidad y de independencia que los árbitros nombrados para un caso específico. El nombramiento permanente aseguraría una mayor independencia, en la medida en que se reducirían los incentivos ante el interés de nombramientos para casos futuros.

En tercer lugar, la existencia de un mecanismo de apelación mejoraría la armonización de las decisiones, aunque podría incrementar la duración y el coste de los procedimientos, lo que iría en detrimento de Estados o inversores con recursos limitados. Este último inconveniente podría mitigarse introduciendo disposiciones que limiten el plazo y el coste de las diferentes fases de un procedimiento.

No obstante, hay quien opina que un tribunal multilateral de inversiones (TMI) permanente no conseguiría atraer como jueces a los mejores candidatos ante la falta de incentivos económicos, y se correría el riesgo de que, al ser nombrados por los Estados, no fueran imparciales. Crítica que no compartimos, dado que existen ya en marcha varios tribunales multilaterales ${ }^{19}$ en los que los árbitros son elegidos por los Estados y no se han dado este tipo de problemas.

\subsection{Antecedentes: iniciativas de reforma antes de la propuesta de la UE}

En 2004 el CIADI propuso la creación de un mecanismo de revisión de los laudos arbitrales $^{20}$ con el objetivo de aumentar la coherencia y la consistencia de la jurisprudencia en materia de inversiones. En el documento del CIADI se establecía que se crearía siendo compatible con cualquier tipo de reglas de arbitraje (CIADI, UNCITRAL u otras) y establecido y gestionado bajo nuevas reglas aprobadas por el Consejo de Administración del CIADI. Su jurisdicción se habría establecido en un tratado internacional con la flexibilidad de que las partes siguieran aceptando el arbitraje sin apelación.

La propuesta del CIADI contemplaba para este mecanismo de apelación un panel de quince individuos de diferentes nacionalidades constituido por el Consejo de Administración del CIADI a nominación del secretario general. El mandato de los miembros del panel sería de tres o seis años y los tribunales de tres miembros serían designados por el secretario general del CIADI tras consultar a las partes.

Se contemplaba la posibilidad de recurrir los laudos por «errores manifiestos en la aplicación de la legislación o errores serios de hecho». El órgano de apelación podía incluso $\triangleright$

19 Como El Tribunal Internacional de Justicia o el Órgano de Solución de Diferencias de la Organización Mundial del Comercio.

20 ICSID Secretariat (2004), pp. 14 f. 
mantener, modificar o anular un laudo o reenviar los casos a los tribunales originales o a nuevos tribunales.

El documento del CIADI que propone un mecanismo de apelación fue público, y se invitó a los Estados parte del CIADI a realizar sugerencias, pero no hubo demasiado interés, por lo que un año después el CIADI concluyó que no había apoyo para la iniciativa.

También el Comité de Inversiones de la $\mathrm{OCDE}^{21}$ exploró un mecanismo de apelación para las disputas de inversión. Sin embargo, la mayoría de los miembros de la OCDE consideraron que se trataba de un cambio radical en el sistema de ISDS, y los debates no progresaron.

Hay que destacar que en algunos acuerdos internacionales de inversiones (All) se han contemplado referencias sobre la creación de un mecanismo de apelación.

En concreto, EE UU contempló esta posibilidad en la autorización para la promoción del comercio $^{22}$ de 2002, en la que se recogía como uno de sus objetivos la mejora del régimen de ISDS mediante un mecanismo de apelación o similar para dar coherencia a las interpretaciones de las disposiciones sobre inversiones. Por esta razón, casi todos los All de EE UU ${ }^{23}$ tienen una referencia sobre un mecanismo de apelación, aunque de manera no vinculante.

Otros tratados que contienen disposiciones similares son los Acuerdos de Libre Comercio (ALC) de Canadá y Corea de $2014^{24}$. No obstante, todas estas disposiciones son no vinculantes, por lo que no han tenido ningún efecto reseñable.

\footnotetext{
21 Yannaca-Small, 2008.

22 Trade Promotion Authority Act (2002), P.L. 107-210, Section 2102(b) (3)(g)(iv), 19 U.S.C § 3802(b)(3)(G)(iv).

23 «2012 US Model Bilateral Investment Treaty». El artículo 28(10) del modelo de All de EE UU recoge una mención expresa a que las partes considerarán si los laudos se someterán a un mecanismo de apelación en el caso de que dicho mecanismo se desarrolle.

24 Anexo 8-E: Possibility of a Bilateral Appellate Mechanism.
}

\subsection{Propuesta de reforma del sistema de protección de inversiones de la UE}

En contraste con los escasos avances obtenidos hasta el momento, se ha producido una considerable aceleración, desde 2015, con la propuesta de la Comisión Europea en las negociaciones de los ALC con sus socios ${ }^{25}$.

La propuesta tiene como finalidad que la protección de inversiones no afecte a la capacidad de regulación de los Estados para conseguir objetivos de interés general. Aunque, sin lugar a dudas, la novedad más importante de esta propuesta es la sustitución del ISDS por un mecanismo de resolución de disputas de carácter permanente.

A mediados de 2014, la Comisión Europea realizó una consulta ${ }^{26}$ pública sobre la existencia de un mecanismo de resolución de disputas inversor-Estado (ISDS) en el acuerdo de comercio con EE UU (TTIP, por sus siglas en inglés). En los resultados de la consulta, la Comisión identificó cuatro áreas de mejora del tradicional sistema ISDS y se comprometió a iniciar un proceso de reforma profunda.

En mayo de 2015, la Comisión presentó un documento ${ }^{27}$ sobre las líneas básicas de reforma del sistema de protección de las inversiones y del mecanismo de resolución de disputas en los acuerdos comerciales con un doble objetivo: 1) garantizar el derecho a regular de los Estados en interés público, manteniendo un alto nivel de protección de los inversores extranjeros, y 2) proponer un sistema bilateral de Tribunal de Inversiones (ICS, por sus siglas en inglés) en los ALC que negocie la UE $D$

\footnotetext{
25 Propuesto con EE UU en el TTIP, incluido en los acuerdos finalizados con Vietnam y Canadá

26 http://trade.ec.europa.eu/consultations/index.cfm?consul_id=179

27 Comisión Europea, 6 de mayo de 2015, Concept Paper «Investment in TTIP and beyond - the path for reform - Enhancing the right to regulate and moving from current ad hoc arbitration towards an Investment Court" (http://trade.ec.europa.eu/doclib/docs/2015/may/tradoc_153408.PDF).
} 
con sus socios, que sea justo e independiente, en lugar de los tradicionales tribunales de arbitraje privados para la resolución de conflictos inversor-Estado.

En este documento, la Comisión indicaba que para establecer un sistema multilateral era necesario desarrollar más el Sistema de Tribunal de Inversiones (ICS, por sus siglas en inglés) con jueces permanentes tanto en el Tribunal de Inversiones como en el Tribunal de Apelación, pudiéndose establecer un sistema de adhesión voluntaria (opt-in) de los diferentes Estados. Este tribunal aplicaría múltiples acuerdos entre distintos socios, podría ser de nueva creación o formar parte de alguna otra institución internacional.

En noviebre de 2015, la Comisión remitió a EE UU su propuesta de texto ${ }^{28}$ sobre protección de inversiones y resolución de disputas que contenía importantes novedades. Las más destacadas son: 1) la inclusión en el texto de un artículo específico reconociendo el derecho de los Estados a regular ${ }^{29}$ en interés público ${ }^{30}$; la no estabilidad del marco legal, incluso aunque dicho cambio afecte negativamente a la gestión de las inversiones cubiertas o a las expectativas de beneficios del inversor, además de apartados relativos al tratamiento de las subvenciones y reestructuraciones de deuda pública; 2) la definición clara de los estándares de protección de inversiones, como el trato justo y equitativo ${ }^{31}$ mediante una lista cerrada de situaciones en las que se entiende que un Estado ha podido violar este principio; la expropiación ${ }^{32}$ en que

\footnotetext{
28 http://trade.ec.europa.eu/doclib/docs/2015/november/ tradoc_153955.pdf

29 Artículo 2, ibíd

30 Objetivos de interés público como, por ejemplo, salud pública, seguridad, medioambiente, moral pública y promoción y protección de la diversidad cultural.

31 Artículo 3, ibíd.

32 Artículo 5, ibíd.
}

se clarifica que el inversor no puede considerar como expropiación los cambios en el marco legal; se incluye además la denominada "cláusula paraguas»33, que implica que un Estado debe respetar sus compromisos por escrito con un inversor; 3 ) pero es en la parte de resolución de disputas donde la propuesta de la UE es más novedosa, proponiendo un Sistema de Tribunal de Inversiones (ICS, por sus siglas en inglés) con importantes diferencias en relación al tradicional ISDS.

\subsection{El Sistema de Tribunal de Inversiones (ICS)}

El sistema tradicional de tribunales arbitrales (ISDS) implica que los árbitros sean elegidos por las partes del conflicto (inversor y Estado) en cada caso, permitiendo que un árbitro haya actuado como abogado o asesor en otros casos. Esta situación puede implicar un conflicto de interés y dudas sobre la imparcialidad en la actuación de los árbitros.

El nuevo modelo de la UE introduce un sistema de doble instancia: un Tribunal de Inversiones como si fuera una primera instancia (TI) y uno de Apelación (TA). El Tribunal de Primera Instancia estará formado por miembros permanentes elegidos por un comité conjunto de las partes del acuerdo, siendo un tercio nacionales de los Estados miembros (EEMM), otro tercio nacionales del socio comercial y el tercio restante nacionales de terceros países. Se crea un mecanismo de apelación para dar consistencia al sistema y evitar la incoherencia en las decisiones del TI. EI TA es competente para conocer laudos del TI $D$

33 Artículo 7. Ibíd. La cláusula paraguas es muy importante para las empresas españolas, en particular en el ámbito de las concesiones y contratos de servicios. 
sobre errores en la aplicación de las normas o de la consideración de los hechos.

Los árbitros son elegidos por las partes del acuerdo, no por las partes de la disputa como en el ISDS. Deben ser personas que cumplan un estricto código ético y de conducta para evitar conflictos de interés y deben tener una alta cualificación e independencia, similar a la de los jueces en los EEMM.

Los miembros del ICS se nombran por periodos de cuatro o cinco años, pudiendo renovarse una vez. Los casos serán juzgados por divisiones de tres miembros, presididos por un nacional de un tercer país. La asignación de los casos se realizará de forma aleatoria. Los miembros del tribunal recibirán una cantidad fija mensual que podrá convertirse en salario mensual si se requiere dedicación plena.

Con respecto al TA, tendrá jurisdicción sobre los laudos emitidos por el Tribunal de Primera Instancia. El comité del acuerdo fijará el número de miembros, aunque en el ALC UEVietnam se fija en seis. Los laudos podrán revisarse bajo las causas recogidas en el artículo 52 de la Convención de CIADI, pero también por errores en la aplicación o interpretación de la legislación o en errores manifiestos en el establecimiento de los hechos. EI TA podrá mantener, modificar o anular un laudo, así como devolver el caso de nuevo al TI.

En cuanto a la ejecución de los laudos o de las decisiones de apelación, si estos son emitidos bajo la Convención de CIADI, serán considerados como una sentencia ejecutable en cualquier país que sea parte de la convención.

Por lo que se refiere a la relación del ICS con los tribunales nacionales, el nuevo modelo de la UE garantiza la compatibilidad entre el marco legal doméstico y las normas internacionales de inversiones, confirmando que la aplicación de la ley doméstica no es competencia del tribunal ICS. EI ICS solo puede tener en cuenta la ley doméstica como una cuestión de hecho «as a matter of fact». Además, cualquier interpretación que haga el ICS sobre la ley doméstica no es vinculante para los tribunales nacionales y debe basarse en la jurisprudencia de esos tribunales nacionales.

Por otro lado, un inversor puede acudir al tribunal del acuerdo siempre que haya retirado cualquier demanda en tribunales nacionales y con la obligación de que si presenta una demanda bajo el ICS ya no podrá hacerlo en los tribunales domésticos (No-u-turn) para evitar doble compensación. Hay que destacar que mientras los tribunales nacionales aplican la legislación nacional, los tribunales ISDS analizan si la actuación de un Estado ha infringido las normas internacionales de inversiones. Esto es especialmente importante cuando las normas de los acuerdos internacionales no son aplicadas de forma directa por los tribunales nacionales, como es el caso en la mayoría de los acuerdos de comercio e inversión que negocia la UE.

El texto incluye una disposición ${ }^{34}$ que contempla la posibilidad de que la resolución de disputas pueda realizarse a través de un Tribunal Multilateral de Inversiones (TMI) en caso de que dicho tribunal se cree a través de un tratado en el que ambas partes lo suscriban.

Tanto en el acuerdo comercial entre la UE y Canadá como entre la UE y Vietnam se contempla la posibilidad de que se establezca en el futuro un TMI.

\footnotetext{
34 Section 3 - Resolution of Investment Disputes and Investment Court System; Article 12: Multilateral dispute settlement mechanisms:

Upon the entry into force between the Parties of an international agreement providing for a multilateral investment tribunal and/or a multilateral appellate mechanism applicable to disputes under this Agreement, the relevant parts of this section shall cease to apply. The [] Committee may adopt a decision specifying any necessary transitional arrangements.
} 
No cabe duda de que la inclusión en estos dos acuerdos de libre comercio de disposiciones sobre un TMI supone una novedad notable con respecto a los anteriores ALC y un claro movimiento de diferenciación con respecto al tradicional mecanismo de resolución de disputas inversor-Estado (ISDS).

\section{Tribunal Multilateral de Inversiones (TMI)}

La creación de un TMI es un tema de candente actualidad, como lo demuestra su inclusión en los foros internacionales más importantes en los que se debate sobre política de inversiones.

En julio de 2016, el tema fue tratado dentro del Foro Mundial de Inversiones de la UNCTAD celebrado en Nairobi. En octubre de 2016, el tema se debatió dentro del Foro sobre Libertad de Inversiones que organiza el Comité de Inversiones de la OCDE. Y, en enero de 2017, en la reunión del Foro Económico de Davos. En todas las ocasiones, la UE y Canadá han liderado este debate sobre la creación de un TMI.

Antes de comenzar a discutir sobre la posible creación de un TMl es necesario realizar una serie de consideraciones relativas al ámbito jurídico del arbitraje de inversiones.

\subsection{Consideración del arbitraje de inversiones dentro de la esfera del Derecho Público Internacional}

Para algunos académicos ${ }^{35}$, el arbitraje de inversiones es similar al sistema judicial de revisión que existe en el Derecho Público. Supone

35 Van Harten, 2008. que un órgano arbitral, en respuesta a una reclamación individual, tiene la competencia para determinar si una medida adoptada por un Estado -basada en su soberanía- implica una posible conducta que viole compromisos asumidos internacionalmente por el Estado.

Además, existe una diferencia conceptual importante entre, por un lado, el arbitraje de inversiones y, por otro, el arbitraje comercial o la resolución de controversias entre Estados (SSDS, por sus siglas en inglés). Tanto el arbitraje comercial como el SSDS son mecanismos que se utilizan para resolver conflictos derivados de una relación legal recíproca entre las partes. En el caso del arbitraje comercial se realizan entre partes privadas (una de las cuales podría ser un Estado actuando de forma privada), mientras que en el caso del SSDS, la resolución de la disputa es ejecutada entre dos Estados que actúan bajo su soberanía, dirimiendo el conflicto en el marco del Derecho Público Internacional. En ambos casos, cada parte tiene la potestad de interponer una reclamación defendiendo los derechos recogidos en el acuerdo.

Sin embargo, en el caso del arbitraje de inversiones, el conflicto surge en un contexto regulatorio, en lugar de en un contexto de obligaciones o derechos recíprocos. Este contexto regulatorio viene definido por la capacidad que tiene el Estado de regular y adoptar medidas basada en su soberanía. Por esta razón, el arbitraje de inversiones se asimila más a una revisión judicial en el ámbito del Derecho Público porque supone que un órgano (un tribunal arbitral en el caso del arbitraje de inversiones) tiene competencia para determinar, en respuesta a una reclamación individual, si un Estado en el uso de su autoridad soberana ha infringido alguna obligación contenida en un acuerdo internacional.

El carácter de Derecho Público de los arbitrajes de inversión viene reforzado por los $D$ 
conflictos que se resuelven en este marco. Habitualmente, los tribunales arbitrales de inversiones dirimen si un Estado ha violado un estándar de protección incluido en un All al aprobar una medida legislativa o administrativa concreta. Por ejemplo, al modificar el régimen de retribución de una energía concreta o al priorizar en el futuro una energía concreta sobre otra.

Es razonable pensar que la decisión que adopte un tribunal arbitral sobre una reclamación de un inversor concreto pueda tener efectos en las empresas de todo un sector, en los consumidores y, en definitiva, en la sociedad. Estas reclamaciones suelen resolverse en el ámbito doméstico por vía administrativa o judicial doméstica. En resumen, podríamos decir que el arbitraje de inversiones se utiliza para resolver disputas entre el que gobierna y los que son gobernados.

Bajo esta interpretación del arbitraje de inversiones, como una cuestión perteneciente al Derecho Público Internacional, tendría sentido la creación de un TMI y exigir la máxima independencia e imparcialidad de los jueces que lo componen. Esto solo puede conseguirse por medio de jueces permanentes que no se vean influidos por presiones externas, tales como ser designados en nuevos procedimientos 0 amenazados por la pérdida de su empleo. La actual configuración del ISDS, en la que los árbitros son nombrados por las partes de la disputa caso a caso, es, obviamente, todo lo contrario a la de jueces permanentes, $y$, por tanto, genera dudas sobre su independencia.

Un TMI sería una especie de «bien público» al servicio de Estados, inversores -salvo quizás para aquellos inversores en los que litigar contra los Estados sea en sí mismo una estrategia de negocio- $-y$ la sociedad en general. En definitiva, se trataría de un sistema en el que los jueces son asignados al caso en función de criterios predefinidos y objetivos, en oposición al sistema actual de selección de árbitros por las partes de la disputa para el caso concreto.

\subsection{Antecedentes de la propuesta de la UE}

La Comisión Europea, en su documento Investment in TTIP and beyond - the path for reform, de 5 de mayo de 2015, expresaba que, en paralelo a la negociación de un sistema bilateral de Tribunal de Inversiones en los acuerdos de la UE (ICS), se iniciaría un trabajo con otros países interesados en crear un Tribunal Multilateral de Inversiones.

Además, la Comisión ha incluido como objetivo en su estrategia de comercio ${ }^{36}$ la cooperación con los socios comerciales a fin de lograr un TMI. En el informe ${ }^{37}$ de la Comisión sobre el estado de la UE, se compromete a adoptar iniciativas para la creación de un TMI, y también lo ha incluido como una iniciativa dentro de su agenda de mejora de la regulación ${ }^{38}$ (Better Regulation Agenda).

Según la Comisión, este TMI podría ser la solución óptima a la reforma del sistema ISDS en términos de legitimidad, efectividad, consistencia y coste asociados con la resolución de disputas de inversión.

\subsection{Consideraciones generales}

La creación de un TMI plantea una serie de cuestiones complejas que es necesario estudiar en profundidad. En particular, sobre su estructura ideal, la adhesión voluntaria o no al $\triangleright$

\footnotetext{
36 Comisión Europea, septiembre de 2015, «Trade for All», pág. 21. (http://trade.ec.europa.eu/doclib/docs/2016/january/tradoc_154134.pdf).

37 Estado de la Unión: progreso en las 10 prioridades de la Comisión.

38 http://ec.europa.eu/trade/policy/accessing-markets/ dispute-settlement/
} 
mecanismo de apelación, la mejor forma de tratar las interpretaciones del acuerdo por las partes, la ejecución de los laudos o los aspectos institucionales.

El planteamiento de la Comisión es que el TMI esté abierto a todos los países y sea competente para resolver disputas bajo los acuerdos de inversión existentes y futuros. Asimismo, en los nuevos acuerdos comerciales de la $\mathrm{UE}^{39}$ se recoge una disposición que establece que este TMI reemplazará al sistema ICS recogido en el acuerdo.

Hay que destacar que la propuesta de la UE de establecer un TMI ha generado gran interés y apoyo de algunos países. De hecho, Canadá ha anunciado públicamente su intención de trabajar con la UE y otros países interesados hacia el establecimiento de este tribunal. Sin embargo, países importantes en la escena internacional como EE UU, Japón o China parece que no son muy partidarios de su creación y defienden la reforma del actual sistema de ISDS. En particular, EE UU es el más reacio, ya que nunca ha perdido un arbitraje de inversiones con el mecanismo actual de ISDS, y además el nivel de críticas de la opinión pública a este sistema es mucho menor que en Europa, por lo que será difícil conseguir su apoyo.

\subsubsection{Legitimidad}

La política de negociar un sistema de Tribunal de Inversiones Bilateral en TTIP, CETA y en todos los demás ALC que negocie la UE ha sido la respuesta a las preocupaciones surgidas, especialmente dentro de la UE, sobre la inclusión del ISDS en TTIP y en otros acuerdos.

39 Este sistema de Tribunal de Inversiones ya se ha incluido en los ALC negociados con Canadá y Vietnam.
Sin embargo, gestionar múltiples tribunales de inversiones en los ALC no puede alcanzar el mismo nivel de legitimidad que un único Tribunal Internacional con jueces permanentes, dedicados exclusivamente a resolver este tipo de disputas.

Un TMI dispondría de la legitimidad derivada de su establecimiento por la comunidad internacional. Además, ya existen tribunales internacionales permanentes ${ }^{40}$.

\subsubsection{Coexistencia entre el TMI y el mecanismo ISDS recogido en los BIT de los EEMM}

El enfoque de la UE de negociar un ICS en cada ALC no afecta a los BIT de los EEMM con disposiciones de ISDS tradicionales, ni al Tratado de la Carta de la Energía en el que tanto la UE como sus EEMM son partes contratantes. En estos acuerdos siguen siendo posibles los casos de ISDS.

No parece factible iniciar una renegociación de todos los $\mathrm{BIT}^{41}$, debido a su complejidad, tiempo y coste. Aunque la conclusión gradual de los nuevos ALC que está negociando la UE con el nuevo modelo de protección de inversiones y de ICS sustituirá a los BIT de los EEMM, este proceso llevará bastante tiempo.

El establecimiento de un TMI daría una solución sencilla y efectiva a los BIT de la UE, haciendo que este TMI fuera competente para $\triangleright$

40 A nivel internacional existen varios tribunales y órganos de solución de conflictos con carácter permanente: el Tribunal Internacional de Justicia, la Corte Penal Internacional, el Tribunal Internacional del Derecho del Mar, el Tribunal Permanente de Arbitraje (aunque este no es un tribunal, sino que facilita la gestión de casos a tribunales que se forman ad hoc, es similar al CIADI) y el órgano de solución de conflictos de la Organización Mundial del Comercio. Para más información sobre este tema, consultar en: http://eur-lex.europa.eu/legal-content/ES/TXT/?uri=URISERV\%3A/16007

41 A fecha de 15 de marzo de 2017 había 2.964 acuerdos internacionales de inversión, de los que los EEMM son parte en 1.763. Fuente: http://investmentpolicyhub.unctad.org/ 
resolver las disputas inversor-Estado. Para conseguir esto se podría utilizar un mecanismo similar al aplicado para las reglas sobre transparencia de UNCITRAL para los acuerdos existentes (la denominada Convención de Mauricio ${ }^{42}$ ).

Bajo esta fórmula, el TMI podría conocer de disputas bajo acuerdos de inversión bilaterales si los países han firmado esta convención en la que aceptaran que la resolución de disputas inversor-Estado fuera conocida por este TMI. En esta convención podría establecerse reservas de acuerdos a aplicar utilizando una lista positiva o negativa ${ }^{43}$.

Esta fórmula tiene la ventaja de que no requiere la modificación de los acuerdos existentes para que se les aplique el TMI, y que ya se ha utilizado para la Convención sobre la transparencia de UNCITRAL.

\subsubsection{Costes y efectividad}

La UE está participando, o tiene previsto hacerlo, en más de veinte negociaciones en las que prevé incluir protección de inversiones y disposiciones de resolución de disputas inversor-Estado.

Como se ha mencionado anteriormente, la existencia de múltiples e independientes tribunales de inversiones en los ALC de la UE será complejo de gestionar, especialmente en cuanto a los procedimientos de selección y nombramiento de jueces y miembros, y en cuanto a los costes. Además, a algunos países en desarroIlo, con los que la UE está negociando ALC, será difícil solicitar que paguen la mitad del gasto de este tribunal bilateral ${ }^{44}$.

\footnotetext{
42 http://www.uncitral.org/uncitral/en/uncitral_texts/ arbitration/2014Transparency_Convention.html

43 La Convención de UNCITRAL utiliza lista negativa.

44 El ALC entre la UE y Vietnam ha sido el primer ejemplo de esta situación, ya que en el texto de servicios e inversiones, capítulo II,
}

Un TMI probablemente costaría mucho menos. Tribunales internacionales comparables tienen un coste en torno a 25 millones de euros anuales $^{45}$. Los costes se repartirían entre los países adheridos al TMI.

\subsubsection{Estructura y funcionamiento del TMI}

La propuesta de la UE plantea un tribunal de inversiones de primera instancia ( $\mathrm{TI}$ ) y un tribunal de apelación (TA). En este sentido, debe establecerse la relación entre ambos tribunales. Por ejemplo, determinar si el TA puede enviar el caso a una instancia inferior (el TI) para revisión. Esto sería muy difícil de conseguir con el sistema actual de tribunales ad hoc, que emiten el laudo y posteriormente se disuelven y dejan de estar activos.

Por lo tanto, sería más lógico tener la primera instancia y la apelación dentro de la misma organización con un carácter permanente, ya que daría mayor consistencia al sistema.

Además, sería razonable que el mecanismo de apelación tuviera la potestad de revisar los laudos de la primera instancia sin que esto implique que exista una dependencia jerárquica.

La cuestión crucial aquí sería definirlo de tal forma que no incremente el coste y los plazos del procedimiento, para hacerlo accesible a empresas pequeñas y medianas, y a Estados con recursos limitados. No obstante, para evitar esta situación, sería muy útil establecer un procedimiento para rechazar de manera $\triangleright$

\footnotetext{
Inversiones, Sección 3, Resolución de disputas de inversión, artículo 12, apartado 15 , se recoge que los costes serán sufragados por las partes del acuerdo «teniendo en cuenta sus niveles de desarrollo respectivos». http://trade.ec.europa.eu/doclib/docs/2016/february/tradoc_154210.pdf (pag. 35).

45 El coste anual del Tribunal Internacional de Justicia de La Haya fue en el bienio 2014-2015 de 51,4 millones de euros. Fuente: Informe anual, pag. 52 (http://www.icj-cij.org/court/en/reports/report_2014-2015.pdf).
} 
rápida las apelaciones manifiestamente carentes de razonamiento («frívolas») tomando como base lo establecido en las Reglas del $\mathrm{CIADI}^{46}$.

De igual forma, es razonable pensar que los laudos de apelación sean definitivos para dar confiabilidad al sistema. La existencia de un mecanismo de apelación mejora la consistencia de los laudos y crearía una jurisprudencia sólida. Esto provocaría un incremento en la confianza en el sistema y su legitimidad.

Un aspecto importante a contemplar sería la existencia o no de la posibilidad de que el Tribunal de Primera Instancia pueda plantear cuestiones prejudiciales al TA. La posibilidad de plantear cuestiones prejudiciales es positiva, ya que aborda problemas de inconsistencia ex-ante en lugar de corregir la posibles deficiencias ex-post, como hace un mecanismo de apelación puro. Además, este instrumento garantizaría interpretaciones uniformes realizadas por un único tribunal y podría hacer que los costes globales del sistema fueran menores para las partes, ya que, en algunos casos, se acortarían los plazos al no existir apelación o tener esta menos sentido. No obstante, habría que resolver la cuestión de que la regulación de inversiones no es homogénea y está incluida en multitud de acuerdos de inversión.

\subsubsection{Coherencia interpretativa}

Los acuerdos de inversión son instrumentos legales con obligaciones para los Estados que los firman. Una redacción poco clara o no detallada de las disposiciones permite a los inversores cuestionar el derecho a regular de los

46 Regla 41, apartado 5.
Estados por el interés público, y a los árbitros gozar de un amplio margen de interpretación, aunque la Convención de Viena ${ }^{47}$ sobre el Derecho de los Tratados establezca normas para la interpretación.

En términos generales, las disposiciones sobre protección de inversiones son comunes en casi todos los acuerdos internacionales de inversiones (trato de nación más favorecida, trato nacional, protección contra expropiación sin compensación, trato justo y equitativo, etcétera), sin embargo, existen diferencias sensibles en cuanto a su consideración (por ejemplo, la del trato justo y equitativo por la UE y por EE UU). Garantizar una interpretación consistente y uniforme en estos acuerdos sería un buen resultado.

Un TMI contribuiría a crear consistencia en la interpretación y el entendimiento de los principios de protección de inversiones, proporcionando previsibilidad y mayor certeza al sistema. Esto mejoraría el marco para la realización de las inversiones y redundaría positivamente en los Estados y en los inversores contribuyendo al crecimiento económico.

\subsubsection{Ejecutabilidad de los laudos del TMI}

Una característica fundamental de un sistema de resolución de disputas inversor-Estado es la ejecutabilidad de los laudos. Existen diferentes reglas de arbitraje, pero las reglas de referencia en este tipo de disputas son las del Centro Internacional de Arreglo de Diferencias relativas a Inversiones (CIADI, o ICSID por sus siglas en inglés), ya que permiten la ejecución del laudo directamente en cualquier país $\triangleright$

47 Suscrita en 1969, entró en vigor en 1980. https://boe.es/boe/ dias/1980/06/13/pdfs/A13099-13110.pdf 
que sea parte contratante de la Convención de CIADI ${ }^{48}$.

Aplicar y retener esta característica de ejecutoriedad es importante en el contexto de la creación de un TMI. Por lo que el acuerdo que constituya el TMI debería replicar esta característica recogida en los artículos 53 y 54 de la Convención de CIADI o, alternativamente, incluir una disposición por la que los Estados que suscriban el acuerdo de creación del TMI consideren sus laudos bajo la Convención de CIADI. Aunque esta última fórmula sería jurídicamente menos sólida y podría generar problemas si los Estados no son parte contratante de la Convención de CIADI.

\subsubsection{Entrada en vigor y adhesión de nuevos miembros}

Un aspecto importante es definir la forma en la que los Estados pueden incluir el TMI a sus acuerdos existentes de inversión. Una opción posible sería utilizar un mecanismo similar a la Convención de UNCITRAL sobre transparencia. Esta convención es un acuerdo internacional por la que los Estados que la firman aceptan aplicar las reglas de transparencia a las disputas que surjan al amparo de acuerdos de inversión en vigor antes de abril de 2014. Su

\footnotetext{
48 El artículo 53 (1) de la Convención de CIADI establece: «El laudo será obligatorio para las partes y no podrá ser objeto de apelación ni de cualquier otro recurso, excepto en los casos previstos en este Convenio. Las partes lo acatarán y cumplirán en todos sus términos, salvo en la medida en que se suspenda su ejecución, de acuerdo con lo establecido en las correspondientes cláusulas de este Convenio".

Por su parte, el artículo 54(1) de la Convención establece que: «odo Estado Contratante reconocerá al laudo dictado conforme a este Convenio carácter obligatorio y hará ejecutar dentro de sus territorios las obligaciones pecuniarias impuestas por el laudo como si se tratare de una sentencia firme dictada por un tribunal existente en dicho Estado. El Estado Contratante que se rija por una constitución federal podrá hacer que se ejecuten los laudos a través de sus tribunales federales y podrá disponer que dichos tribunales reconozcan al laudo la misma eficacia que a las sentencias firmes dictadas por los tribunales de cualquiera de los Estados que lo integran».
}

entrada en vigor se producirá seis meses después de que tres países la hayan ratificado ${ }^{49}$.

Un acuerdo de este tipo podría ser el instrumento jurídico por el que los Estados expresaran su consentimiento a que las disputas de inversiones fueran resueltas en el TMI.

Utilizar una convención es la fórmula más eficiente por varias razones. En primer lugar, tendría los mismos efectos que la renegociación de los All pero con la ventaja de no tener que recurrir a complejos procedimientos de modificación de los All existentes. El resultado final sería la existencia de un instrumento jurídico internacional que coexistiría con los All, complementando sus disposiciones relativas a la resolución de disputas con efecto automático. En segundo lugar, la convención podría recoger una serie de reservas de aplicación en función de diferentes criterios (acuerdo en concreto, fecha de aplicación, excluir determinados principios de protección de inversiones, o aplicación en función de si el Estado origen del demandante es parte o no de la Convención de CIADI o de otro instrumento de inversión, etcétera), permitiendo mayor flexibilidad para que los Estados se adhieran.

Aunque el objetivo es que el TMI tenga la máxima cobertura posible, es aconsejable permitir su entrada en vigor con un número reducido de Estados para crear tracción para futuras adhesiones.

\subsubsection{Configuración inicial institucional y geográfica}

La creación de un TMI plantea aspectos estructurales importantes. El primero es dónde $\square$

49 A 15 de marzo de 2017, la convención ha sido firmada por 18 Estados y ratificada por otros dos (Mauricio y Canadá). https://treaties.un.org/Pages/ ViewDetails.aspx?src=TREATY\&mtdsg_no=XXII-3\&chapter=22\&clang=_en 
se ubicaría el tribunal dentro del sistema institucional internacional. Existen varias alternativas, de las cuales pueden destacarse las dos siguientes: incluirlo en una institución ya existente o crear un nuevo organismo internacional.

1. Incluir el TMI en una organización internacional ya existente. Hay varias instituciones internacionales que podrían ser candidatas a albergar el futuro TMI. Sería necesario tener en cuenta varias circunstancias sobre esta opción, como la experiencia en resolución de disputas, la experiencia en Derecho Internacional de Inversiones, las reglas de pertenencia y de voto, la imagen de la institución, etcétera.

2. Crear una nueva institución. Una nueva institución que cree el TMI tiene la ventaja de que los negociadores tendrían mayor libertad para diseñar un sistema efectivo sin necesidad de adaptarlo a un sistema o institución ya existente o sin tener en cuenta el componente político de dicha institución.

Es importante garantizar el objetivo de que un TMI no dependa del consenso de un gran número de países, pues eso dilataría su conformación.

En mi opinión, sería más beneficioso crear una nueva institución para evitar el sesgo de incluirlo en un organismo ya existente, y, una vez creado el TMI, podrían firmarse acuerdos con los principales organismos de arbitraje (CIADI, PCA, Cámara de Comercio de Estocolmo, etcétera).

\subsubsection{Tratados internacionales a tener en cuenta}

La creación del TMI debería tener en cuenta su relación con el Derecho Internacional, especialmente con la Convención de Viena sobre el
Derecho de los Tratados ${ }^{50}$, la Convención sobre resolución de disputas de inversión inversor-Estado de CIADI y la Convención de Nueva York sobre reconocimiento y ejecución de los laudos arbitrales.

\subsubsection{Composición del TMI}

A la hora de definir la composición del TMI es importante establecer un mecanismo que garantice su imparcialidad e independencia. Sin embargo, al tratarse de un tribunal multilateral, además hay que establecer un proceso de elección de los miembros del tribunal que sea aceptable para todos o la gran mayoría de los Estados que formen parte de la constitución de dicho tribunal.

En este sentido, sería razonable utilizar mecanismos ya existentes y aceptados en algunos organismos internacionales como, por ejemplo, el Tribunal Internacional de Justicia o el Órgano de Solución de Diferencias de la OMC. Es importante eliminar cualquier riesgo de «politizar» la elección de los miembros, por lo que sería necesaria máxima transparencia en el proceso de selección.

Otro aspecto importante a tener en cuenta es la determinación del plazo de mandato de los miembros del tribunal y el número de miembros. Con respecto a la duración, un plazo largo sin reelección ${ }^{51}$ daría mayor independencia a los miembros, ya que evitaría presiones de los Estados. Respecto al número de miembros del tribunal, depende de si se prefiere un órgano permanente (en este caso el número $D$

\footnotetext{
50 Técnicamente, la Convención de Viena sobre el Derecho de los Tratados (1969) no es aplicable a la Convención del CIADI (1965), ya que su artículo 4 establece que solo se aplica a acuerdos finalizados después de su entrada en vigor.

51 La Corte Europea de Derechos Humanos modificó, en 2010, el período de mandato de seis años renovable a un período de nueve años no renovable con la intención de incrementar la independencia e imparcialidad de sus miembros.
} 
sería reducido) o un listado de miembros con un carácter «semipermanente» (aquí sería necesario un mayor número).

A la hora de juzgar los casos entre un inversor y un Estado sería conveniente establecer restricciones de nacionalidad en la composición del tribunal, así como criterios de selección predefinidos. La razón de estas restricciones es que, en gran número de ocasiones, las disputas de inversión, a diferencia de las disputas comerciales, afectan a cuestiones de interés público ${ }^{52}$ sometidas a presión política y de opinión pública.

\section{Conclusiones}

La creación de un Tribunal Multilateral de Inversiones que resuelva disputas inversor-Estado supone una transformación importante frente al actual sistema de tribunales arbitrales privados que se constituyen caso a caso, o también denominado ISDS.

EI TMI tendría una función judicial configurada como un sistema de doble instancia, con posibilidad de apelación. Sus miembros serían elegidos de forma transparente con el máximo nivel de cualificación y sujetos a un estricto código de conducta para garantizar la independencia y minimizar los conflictos de interés.

Este TMI supone un movimiento hacia una institución permanente, que daría mayor estabilidad y certidumbre al marco internacional de inversiones, lo que contribuiría a apoyar el crecimiento económico.

No obstante, como en todo proceso de creación de un nuevo mecanismo o acuerdo de

\footnotetext{
52 Como por ejemplo, decisiones sobre cambiar la agenda energética de un país y dejar de promocionar un tipo de energía (nuclear, renovable, etcétera); medidas para preservar la salud pública; disputas relacionadas con derechos fundamentales; entre otros.
}

ámbito internacional, surgen importantes interrogantes en cuanto a su éxito.

En mi opinión, uno de los principales condicionantes para el éxito del TMI proviene del, hasta ahora, escaso apoyo o interés de países importantes en la escena internacional como EE UU, Japón o China. Además, será importante implicar en el proceso de creación a la opinión pública, de forma que sea una institución de máxima legitimidad.

\section{BIBLIOGRAFÍA}

[1] BIAC (2016). Why International Investment Agreements Matter (marzo). Disponible en: http://biac.org/wp-content/uploads/2016/07/ FIN-2016-03-IIA11.pdf

[2] COMISIÓN EUROPEA (2015). Text sent to the United States on investment protection and investment dispute resolution (12 de noviembre). Disponible en: $h$ ttp://trade.ec.europa.eul doclib/docs/2015/november/tradoc_153955.pdf

[3] COMISIÓN EUROPEA (2015). Factsheet on investment. Disponible en: http://trade.ec.europa.eu/doclib/docs/2015/january/tradoc_153018.5\%20lnvestment.pdf

[4] COMISIÓN EUROPEA (2015). Investment in TTIP and beyond - the path for reform (4 de mayo). Disponible en: http://trade.ec.europa. eu/doclib/docs/2015/may/tradoc_153408. $P D F$

[5] COMISIÓN EUROPEA (2015). Why the new EU proposal for an Investment Court System in TTIP is beneficial to both States and investors (12 de noviembre). Disponible en: http://europa.eu/rapid/ press-release_MEMO-15-6060_en.htm

[6] ICSID (2004). Possible improvements of the framework for ICSID arbitration. Disponible en: http://www.iisd.org/library/comments-icsid -discussion-paper-possible-improvementsframework-icsid-arbitration

[7] KAUFMANN-KOHLER, G. y POTESTÀ, M. (2016). Can the Mauritius Convention serve as a model for the reform of investor-State arbitration in connection with the introduction of a permanent investment tribunal or an appeal $\triangleright$ 
mechanism? Analysis and roadmap. Geneva Center of International Dispute Settlement. Disponible en: http://www.uncitral.org/pdf/ english/CIDS_Research_Paper_Mauritius.pdf

[8] KUMARI, J. (2014). «Foreign Direct Investment and Economic Growth: A Literature Survey». BVIMSR's Journal of Management Research, vol. 6. Issue 2 (October) p.121. Disponible en: http://www.bvimsr.com/documents/publication/2014V6N2/04.pdf

[9] UNCTAD (2014). Transformation of the international investment agreement regime, (Note by the secretariat, diciembre). Disponible en: http://unctad.org/meetings/en/Sessional Documents/ciiem4d2_en.pdf

[10] VAN HARTEN, G. (2008). «A Case for an International Investment Court». All Papers. Paper 259. Disponible en: http://digitalcommons.osgoode.yorku.ca/cgi/viewcontent. cgi?article $=1258 \&$ context $=a l l \_p a p e r s$

[11] YANNACA-SMALL, K. (2006). «Improving the System of Investor-State Dispute Settlement». OECD Working Papers on International Investment, 2006/01, OECD Publishing. Disponible en: $h$ ttp://dx.doi.org/10.1787/631230863687

\section{SIGLAS UTILIZADAS EN EL ARTíCULO}
All Acuerdo internacional de inversión
ALC Acuerdo de libre comercio
APPRI Acuerdo bilateral de promoción y protec- ción de inversiones
BIT Tratado bilateral de inversiones (siglas en inglés de Bilateral Investment Treaty)

CETA Acuerdo Económico y Comercial Global entre la Unión Europea y Canadá (siglas en inglés de Comprehensive Economic Trade Agreement)

CIADI Centro Internacional de Arreglos de Diferencias Relativas a Inversiones

ICS Sistema de Corte de Inversiones (siglas en inglés de Investment Court System)

ICSID Centro Internacional de Arreglos de Diferencias Relativas a Inversiones (siglas en inglés de International Centre for Settlement of Investment Disputes)

IED Inversión extranjera directa

ISDS Solución de controversias entre inversores y Estados (siglas en inglés de investor to State dispute settlement)

NMF Nación más favorecida

OCDE Organización para la Cooperación y el Desarrollo Económicos

OMC Organización Mundial del Comercio

SSDS Solución de controversias entre Estados (siglas en inglés de State to State dispute settlement)

TA Tribunal de apelación

TI Tribunal de inversiones

TJE Trato justo y equitativo

TN Trato nacional

TTIP Acuerdo Transatlántico sobre Comercio e Inversión entre la UE y EEUU (siglas en inglés de Transatlantic Trade and Investment Partnership)

UNCTAD Conferencia de las Naciones Unidas sobre Comercio y Desarrollo (siglas en inglés de United Nations Conference on Trade and Development)

TMI Tribunal Multilateral de Inversiones 
Información Comercial Española

Revista de Economía

6 números anuales

Artículos originales sobre un amplio espectro de temas tratados desde

una óptica económica, con especial referencia

a sus aspectos internacionales

Boletín Económico

de Información Comercial Española

12 números anuales

Artículos y documentos sobre economía española, comunitaria e internacional, con especial énfasis en temas sectoriales $\mathrm{y}$ de comercio exterior
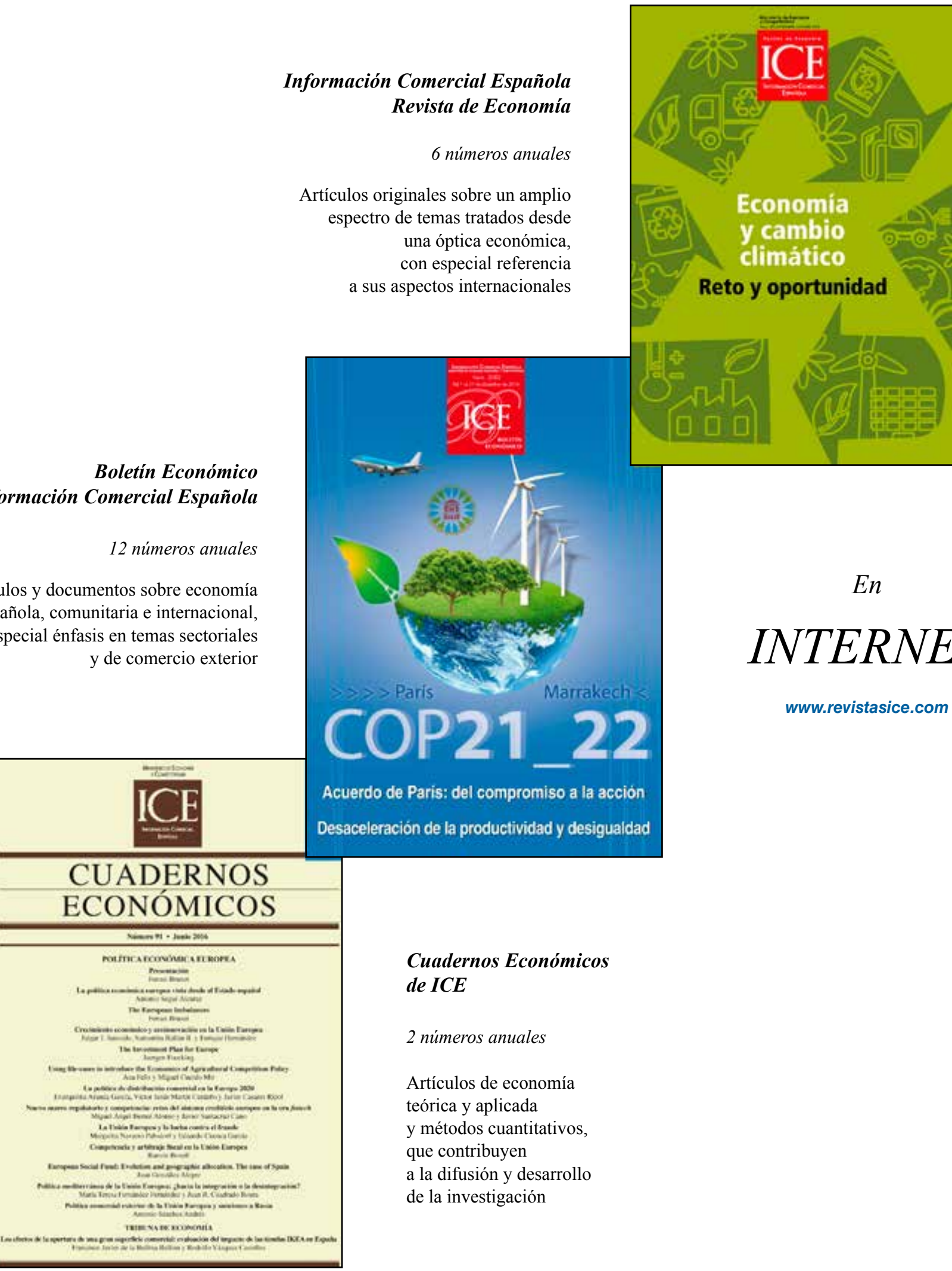

\section{Cuadernos Económicos de ICE}

2 números anuales

Artículos de economía teórica y aplicada y métodos cuantitativos, que contribuyen a la difusión y desarrollo de la investigación

\section{INTERNET}

www.revistasice.com 